Journal of Science

\title{
Failure Analysis of a Drop Tested Wall-Mounted Air Conditioner Indoor Unit: Simulation and Experimental Analysis
}

\author{
Pasa YAYLA ${ }^{1, *(D)}$, Mehmet Fazlı TEKNECI ${ }^{2}$ (it) \\ ${ }^{1}$ Marmara University, Engineering Faculty, Mechanical Engineering Department Göztepe Campus 34722 Kadıköy, Istanbul, Turkey \\ ${ }^{2}$ Sabiha Gökçen International Airport, No: 3, E Gate, 34912, Pendik, İstanbul, -Turkey \\ Highlights \\ - This paper focused on failure analysis of electric-electronic goods subjected to drop test. \\ - The problem was analysed analytically and numerically and the results are compared. \\ - A good correlation was obtained between experimental and simulated numerical results.
}

\begin{tabular}{l} 
Article Info \\
\hline Received: $12 / 01 / 2020$ \\
Accepted: 26/05/2020 \\
Keywords \\
\hline Drop test \\
Failure analysis \\
Finite element method \\
Air conditioner unit \\
Packaging
\end{tabular}

\begin{abstract}
Dynamic behaviour of a wall-mounted air conditioner indoor unit is analysed under drop impact condition. For simulation analysis, a finite element analysis code, known as Ansys Autodyn, is used. Physical drop tests are performed according to ASTM D5276 and ASTM D880 standards and strain gauges are used to measure the effective strains by attaching to specific areas subjected to excessive deformation. By recording drop test with high speed camera, the impact contact duration is also detected. By comparing experimental and numerical results, the validation of finite element analysis is performed. Product improvements are made for the damaged areas and validated by drop test. Conducting physical drop tests with strain gauges together with finite element analysis decreases product development lead time, reduces development costs and eliminates the product's potential risks in advance. The approach presented with this work can be a reference guide for assessing the dynamic response of impact sensitive home and industrials applicants.
\end{abstract}

\section{INTRODUCTION}

Commodity goods, home appliances and electronic equipment may undergo some accidental loading conditions such as striking, crushing and dropping etc. during logistics. Unforeseen logistic conditions, inappropriate carrying conditions during transportation may induce failure in some critical plastic parts or plastic deformation in some sheet metal based parts. These occurrences may result in not only mulfunctioning of the product but also customer dissatisfaction.

In order to overcome these potential problems, parts manufactured form Expandable Polystyrene (EPS) material are widely used as the packaging material for these impact sensitive goods. The parts made from EPS material are the most extensively used ones because of their high impact absorber properties. To check whether EPS parts are enough to prevent possible damages or not, drop tests in Arçelik-LG Company are carried out according to ASTM D5276 [1] and ASTM D880 [2]. Whether these destructive test results are good or not, the product becomes scrap. Not able to see weak points of the product and its packaging as a result of drop test in advance causes repeating the test again and again. This trial and error testing process increases the development cost and delays the product launch time.

There are a number of different works on drop test for such delicate costumer goods such as oven [3-4], washing machine [5], dishwasher [6-7], refrigerator [8] etc. and for electronic devices such as optical pickup 
[9], television [10-11], test board [12], portable electronic devices [13], mobile phone [14] and microelectronic solder joints [15].

In these studies, the strength and mechanical properties of EPS are examined, Finite Element Method (FEM) is used and the numerical results are compared with the physical drop tests.

For an air conditioner indoor unit there is not any study for preventing such transportation caused problems until now.

In this study strain gauges are attached to critical locations of the unit to measure stress at those points during drop test. Finite Element Analysis (FEA) code, known as Ansys Autodyn commercial code, is performed to analyse the drop test of an air conditioner indoor unit. By the comparing of strain gauge measurements and FEM analysis results, validation of analysis method is carried out. Subsequently, some improvements are implemented for damaged parts. Analysis and drop test are repeated after each improvement and results are compared. After validating the accuracy of numerical modelling results with experimental ones, the improvements on product is finalized and these improves are validated with experiments and numerical analysis.

The flow chart of this study is presented in Figure 1.

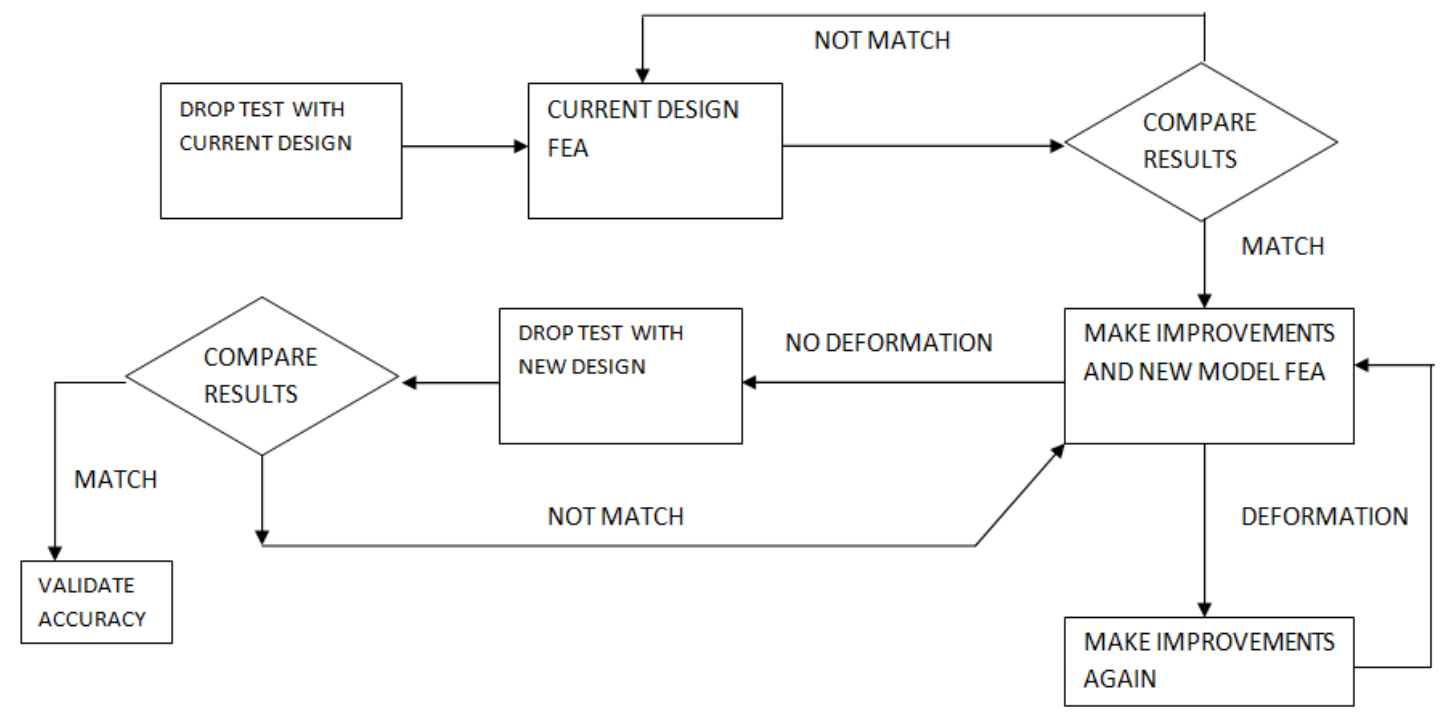

Figure 1. Flow chart of the analysis procedure

\section{MATERIAL PROPERTIES USED IN FEM MODEL AND PHYSICAL TESTS}

In the FEM analysis, the bottom plate which air conditioner indoor unit strikes during drop test can be considered as rigid and no deformable. Plastic parts, decor and discharge grille are made of resin ABS and PP respectively. The material properties of plastic parts taken into account in the FEA analysis is tabulated in Table 1.

Table 1. Material properties of plastic parts

\begin{tabular}{|l|c|c|c|}
\hline $\begin{array}{c}\text { Material } \\
\text { Type }\end{array}$ & $\begin{array}{c}\text { Density } \\
\left(\mathbf{k g} / \mathbf{m}^{\mathbf{3}}\right)\end{array}$ & $\begin{array}{c}\text { Elastic Modulus } \\
(\mathbf{G P a})\end{array}$ & $\begin{array}{c}\text { Poisson's } \\
\text { Ratio }\end{array}$ \\
\hline Plastic, ABS & 1180 & 2,89 & 0,23 \\
\hline Plastic, PP & 950 & 1,6 & 0,43 \\
\hline
\end{tabular}


For ABS and PP plastic parts average stress strain curves are taken into consideration during FEA. Any strain rate dependency of these material properties is not taken into consideration in this study and has not been encountered in previous studies as well.

Some parts of air conditioner such as fan motor, control box took part in Finite Element Model are modelled as mass elements. Only weight of them is taken in consideration.

Expanded Polystyrene (EPS) foams are widely used in protective applications as a cushioning packing material for home appliances, electronic devices and so on because of its energy absorptive ability. When exposed to any impact, they are easily damaged so not suitable for repetitive impacts.

Compressive stress-strain curve of EPS has three zones as shown in Figure 2. At the first zone the relationship between stress and strain is relatively linear. Energy absorption occurs mostly at zone 2, and deformation ends at zone 3 .

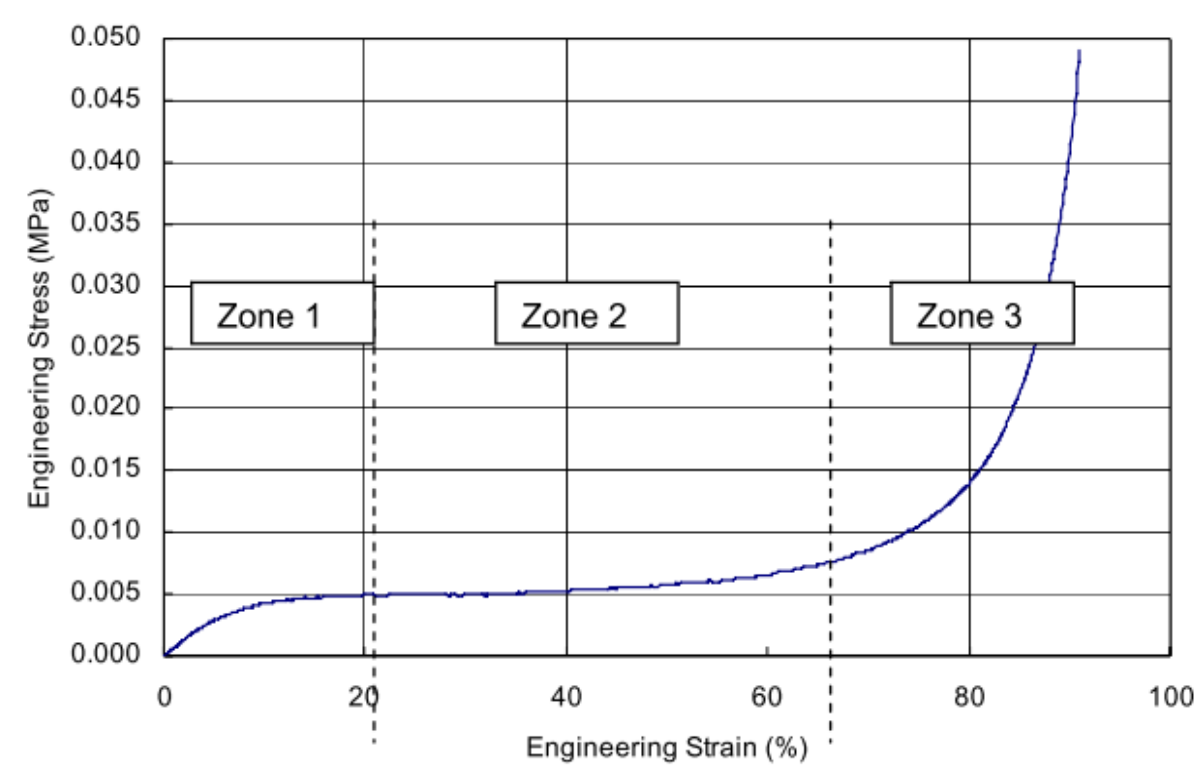

Figure 2. Three deformation zones of EPS [3]

Stress-strain of EPS curve can vary according to strain rate as shown in Figure 3. For a certain strain value, the stresses increase with the increasing of strain rate. The stress-strain curve also depends on the density and direction of impact of the EPS. 


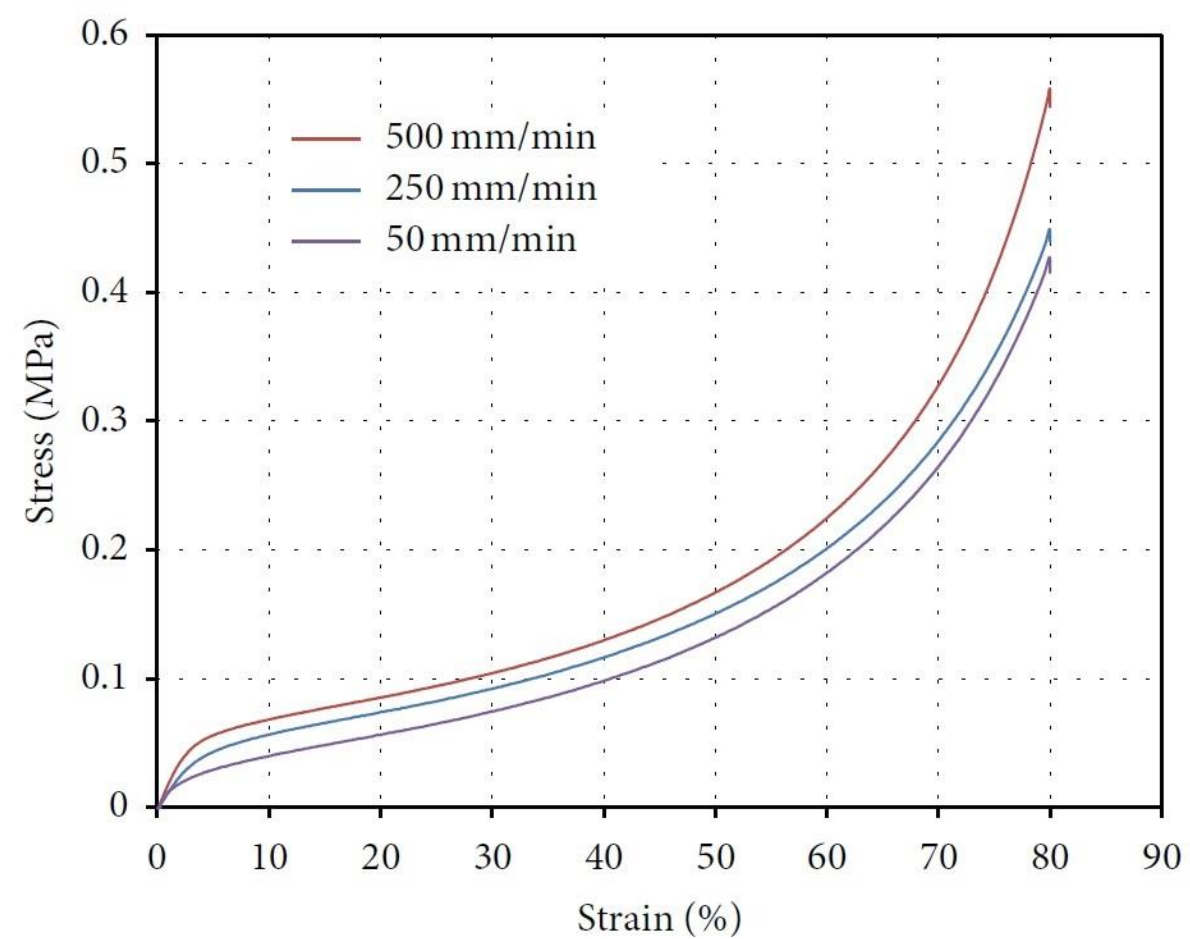

Figure 3. Rate dependency of EPS crushable foam [16]

In these tests, the product drop height of $50 \mathrm{~cm}$ and impact velocity of $3132 \mathrm{~mm} / \mathrm{s}$ are taken into account. At a similar study on dishwasher [7], experiments are performed to study the effect of strain rate on stressstrain curve. For EPS foam which has a density of $20 \mathrm{~kg} / \mathrm{m}^{3}$, the obtained curve is as shown in Figure 4.

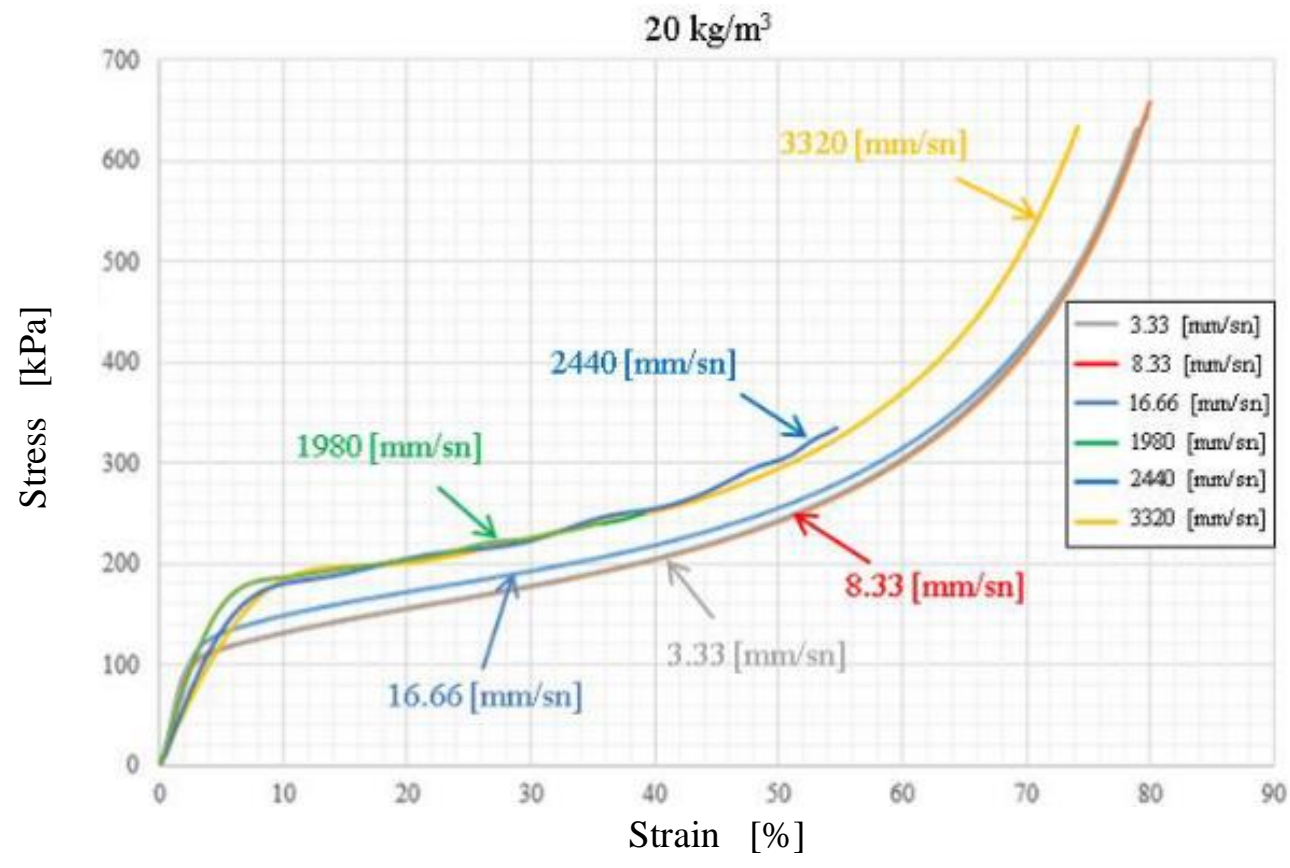

Figure 4. Variation of stress-strain curve with the change of strain rate [7]

Due to the proximity of our $3132 \mathrm{~mm} / \mathrm{s}$ value, $3320 \mathrm{~mm} / \mathrm{s}$ curve are taken into consideration in this study. For the other properties BASF values [16] are taken into account in Finite Element Analysis and given in Table 2 . 
Table 2. Properties of EPS [16]

\begin{tabular}{|l|c|c|}
\hline PROPERTIES & Unit & Value \\
\hline Density & $\mathrm{kg} / \mathrm{m}^{3}$ & 20 \\
\hline Compressive stress at $10 \%$ compression & $\mathrm{kPa}$ & $110-140$ \\
\hline Modulus of elasticity & $\mathrm{MPa}$ & $3,5-4,5$ \\
\hline Permitted compressive stress for packaging calculations & $\mathrm{kPa}$ & 39 \\
\hline Shear strength & $\mathrm{kPa}$ & $124-154$ \\
\hline Tensile strength & $\mathrm{kPa}$ & $230-330$ \\
\hline
\end{tabular}

\section{DROP TEST PLATFORM WITH STRAIN GUAGES}

A gravity driven drop test is widely used to study of how well a product survives for the impact resulting from being dropped in a gravitational field from a desired height onto a certain surface.

Products must be able to performed as expected after being subjected to foreseen loading scenario. The drop may be due to either standard daily use of the product or to an accidental occasion (i.e., probable misuse of the product or unsuitable carrying conditions). A gravity driven drop tests are regularly carried out on the prototype of the final design, since the cost of the real product and the related testing systems required to perform the physical drop test may be quite high. Different types of lifting product by drop test platform of Arçelik-LG Company (Turkey) is presented in Figure 5.

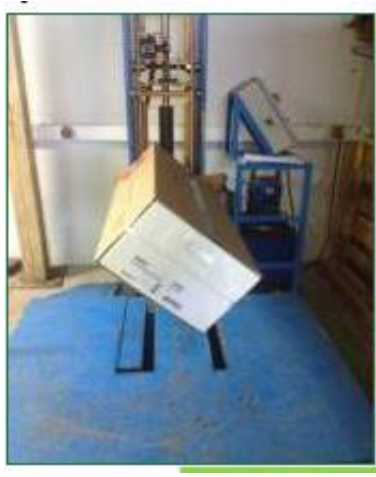

1. Back Edge

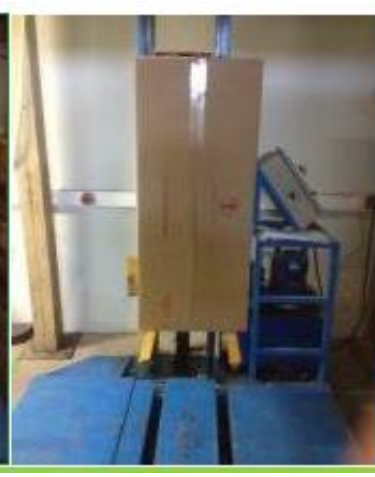

2. Left Side

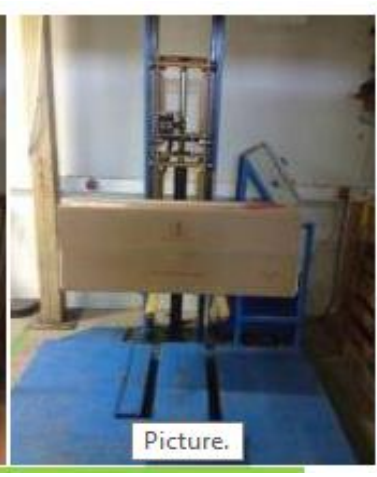

3. Front Side
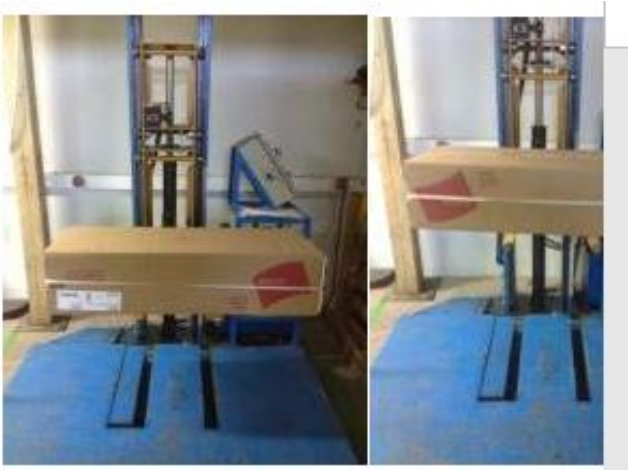

3. Bottom Side

3. Top Side

Figure 5. Lifting types of product by drop test machine

A strain gauge converts force, pressure, tension, weight, etc., into a change in electrical resistance. For the measurement of mechanical quantities, strain gauges can be considered as one of the most effective sensor. Strain is defined as the amount of deformation per unit length of an object when a load is applied. Strain is calculated by dividing the total deformation length $(\Delta \mathrm{L})$ by the original length $(\mathrm{L})$ :

$$
\text { Strain }(\varepsilon)=(\Delta \mathrm{L}) / \mathrm{L}
$$

Maximum principal stresses are calculated in terms of measured strains with Equation (1) [17];

$$
\sigma_{1,2}=E\left(\frac{\varepsilon_{x}+\varepsilon_{y}}{2(1+v)} \pm \frac{1}{2(1+v)} \sqrt{\left(\varepsilon_{x}-\varepsilon_{z}\right)^{2}+\left(2 \varepsilon_{y}+\left(\varepsilon_{x}+\varepsilon_{z}\right)\right)^{2}}\right)
$$


where the $\mathrm{E}$ is the elastic modulus, $\mathrm{v}$ is the Poisson's ratio, $\varepsilon_{\mathrm{x}}$ is the strain in $\mathrm{x}$ direction, $\varepsilon_{\mathrm{y}}$ is the strain in $\mathrm{y}$ direction, $\varepsilon_{z}$ is the strain in $\mathrm{z}$ direction, and $\sigma_{1,2}$ are the principle stresses.

Von Mises stress is calculated in terms of principle stresses with Equation (2) [17];

$$
\sigma_{\text {VonMises }}=\left|\sqrt{\left(\sigma_{1}^{2}-\sigma_{1} \sigma_{2}+\sigma_{2}^{2}\right)}\right| \text {. }
$$

These von Mises stress values are recorded for comparing with the ones obtained from the FEA.

In this study the indoor unit is dropped to bottom side and front side. First strain gauges are attached the right hook of decor part and the second ones are attached to left hook of discharge grille as shown in Figure 6. All the initial drop tests performed on the air conditioner indoor unite indicated that these locations of the product were the most severely damaged zones in the drop tests.

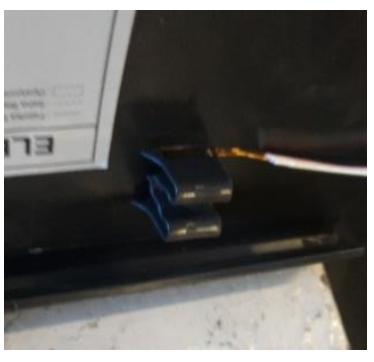

Figure 6. a) Hook of décor

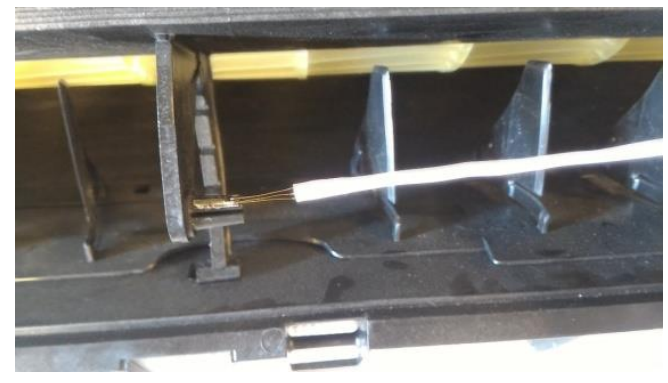

b) Hook of discharge grille

By the help of below equipment shown in Figure 7, a network between indoor unit and computer is created. A universal recorder is used to record strain values and transmit to software. After that with the help of software program the stress values on the gauge attached locations are calculated as shown in Figure 8.

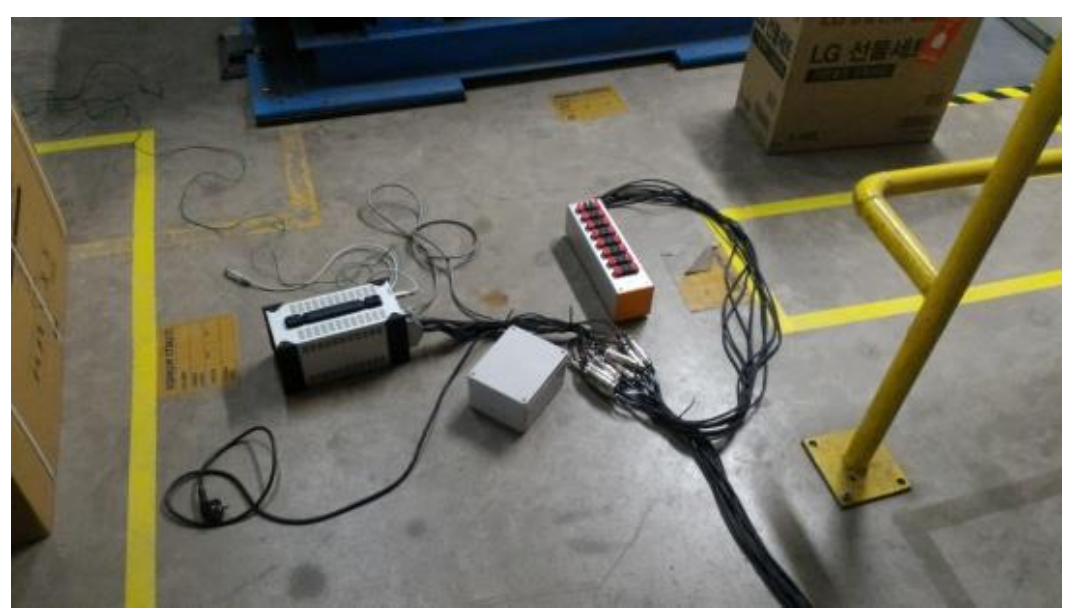

Figure 7. Strain gauge network equipment 


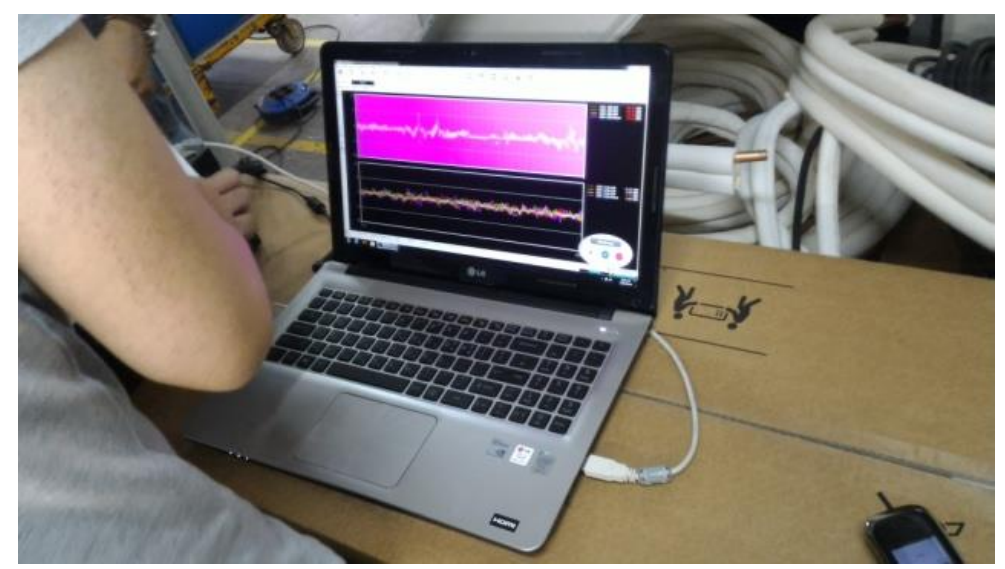

Figure 8. Strain gauge software program

The whole drop test event is recorded with high speed camera having the capability of recording 120 frames per second. Impact duration is detected as $40 \mathrm{msec}$.

\section{FINITE ELEMENT MODELLING}

The Finite Element (FE) method is a numerical solution that seeks solutions to various engineering problems with an acceptable approach. In today's competitive environment, it is essential to reduce the amount of prototype testing and to simulate verify designs that are not suitable for prototype testing.

For the FE analysis, explicit nonlinear finite element software program "ANSYS Autodyn" is used. Because it is rather user friendly to be used for multiphysics problems and sophisticated material response. Furthermore the program is also well suited for designers and analysts aiming to use Ansys Workbench to easily solve complex problems. Thus ANSYS Autodyn significantly simplifies the analysis associated with conducting a drop test simulation.

Firsts of all, all the parts of indoor unit are created separately at Creo parametric 3D design program. Then the assembly file is made by these parts. It can be seen décor, discharge grille and full assembly data in Figure 9. This assembly data is saved as a step file in order to import it Ansys.

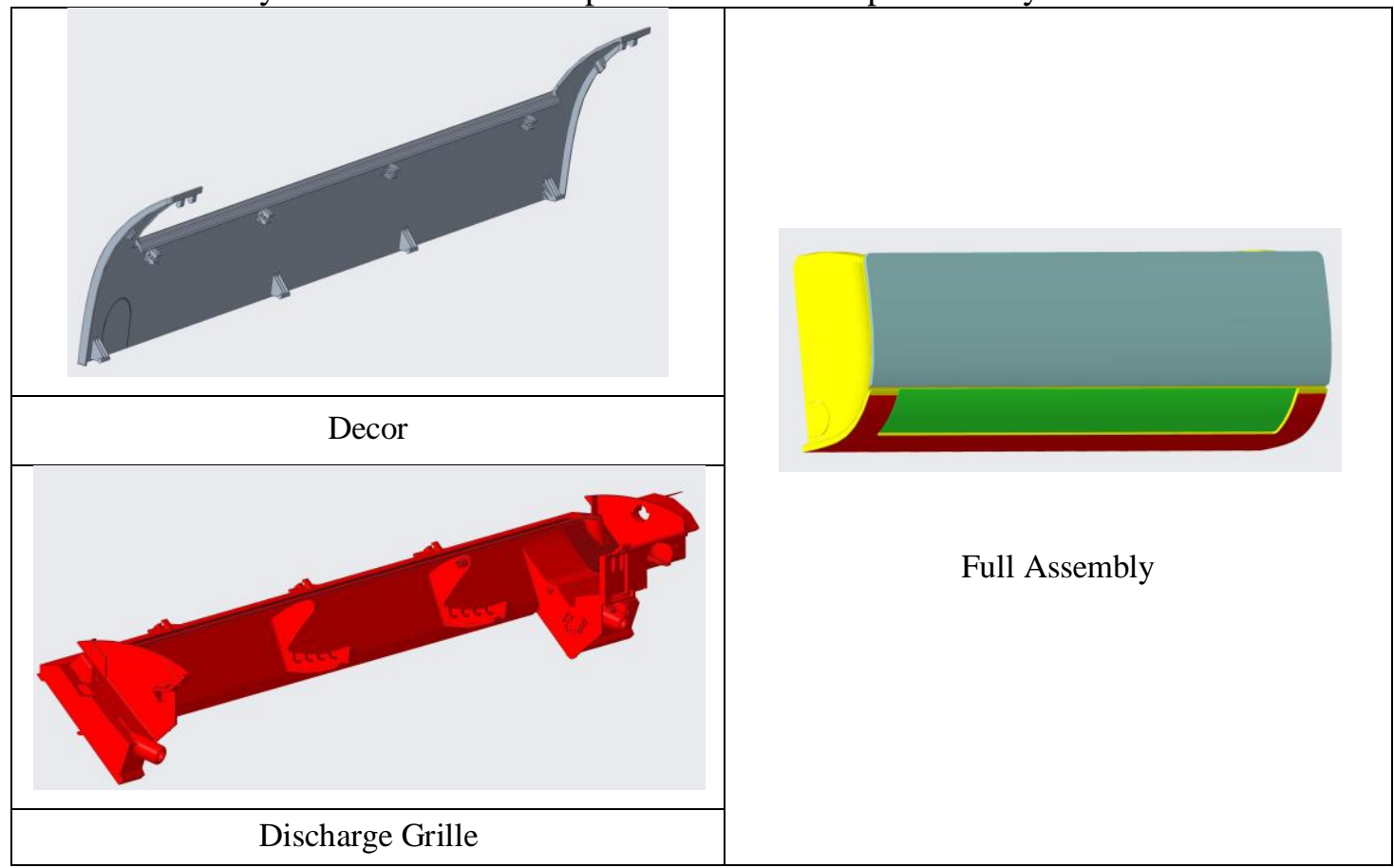

Figure 9. 3D Data of Décor 
Firstly, Ansys Workbench is opened and an explicit dynamic file is created. Second step is determining materials from "Engineering Data" section. For decor part ABS, for discharge grille PP and for cushioning parts EPS materials must be selected. Since Ansys Library includes none of them, ABS, PP and EPS properties are introduced to Ansys Library [18-19] from previous work [7]. All parts connections are defined. In this study, two different type connection are used; namely bonded and frictional. The parts connected to each other with a screw is considered as bonded, and other ones are defined as frictional connection.

The mesh generation of the problem is achieved by Ansysmesh. Triangular mesh type is implemented in the analysis due to its effectiveness for this kind of analysis. This type of mesh is also used in previous drop and crash study [3]. The finer mesh may give more accurate results, but it also increases SPU duration. Thus, for more critical regions, such as décor and discharge grille, the mesh size is $0.5 \mathrm{~mm}$ but for other regions of the indoor unit it ranges up to $8.0 \mathrm{~mm}$. Totally 658715 elements are generated as shown in Figure 10.

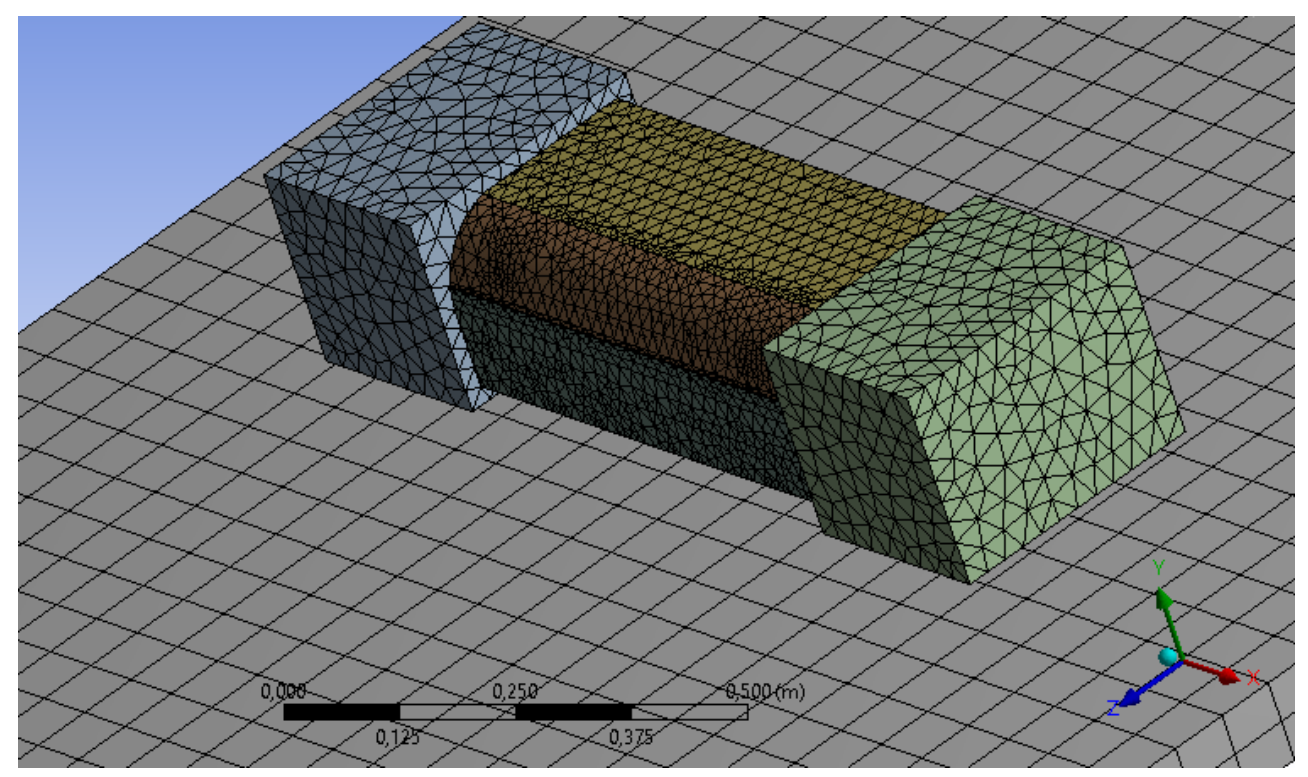

Figure 10. Mesh generated assembly (main dimensions are $240.60 \mathrm{~mm}, 1100.40 \mathrm{~mm}$ and $320 \mathrm{~mm}$ as height, length and width, respectively)

In the drop test, the indoor unit is freely dropped into a rigid ground from the height of $0.5 \mathrm{~m}$. The velocity at the time of impact is calculated automatically by the software program with the Equation (3)

$$
V o=\sqrt{2 g h},
$$

where $V_{o}$ is the impact velocity, $h$ is the height of indoor unit dropped on test and $g$ is the acceleration of gravity.

$$
V o=\sqrt{2 x\left(\frac{9,8066 m}{s 2}\right) \times 0,5 m},
$$

$V o=3,1315 \mathrm{~m} / \mathrm{s}$. 


\section{RESULTS AND DISCUSSIONS}

In this study only two different type drop tests are conducted. The air conditioner indoor unit is dropped to its front side and bottom side. Thus finite element analysis is performed according to these two types. When the product is dropped to its front side, the hook of discharge grille is severely distorted both at the real test and the simulation, as shown in Figure 11a and 11b, respectively.

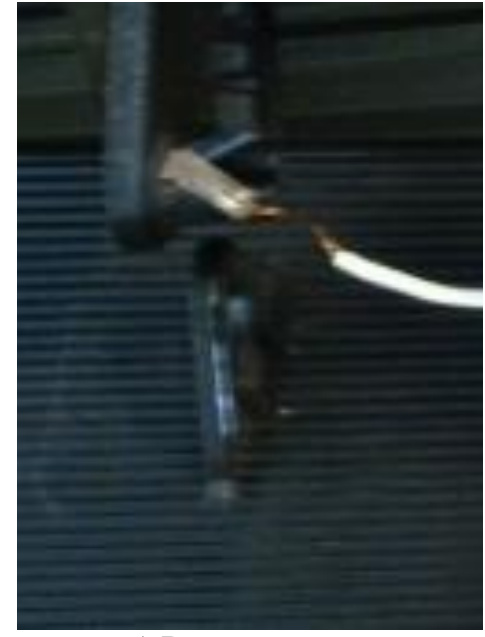

a) Drop test

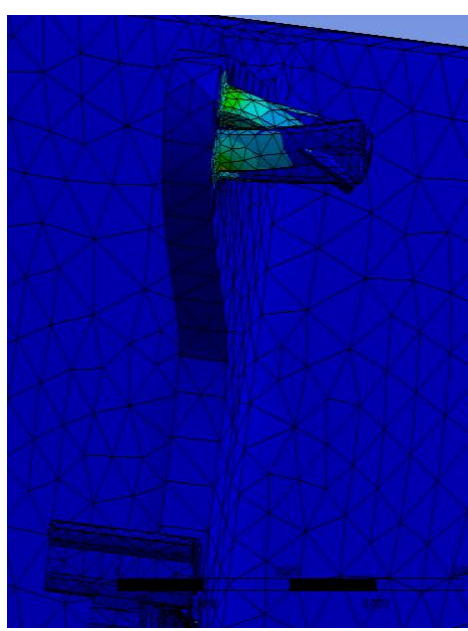

b) Finite Element Analysis

Figure 11. Deformation of discharge grille hook

Hook of decor part fractured as shown in Figure 12.

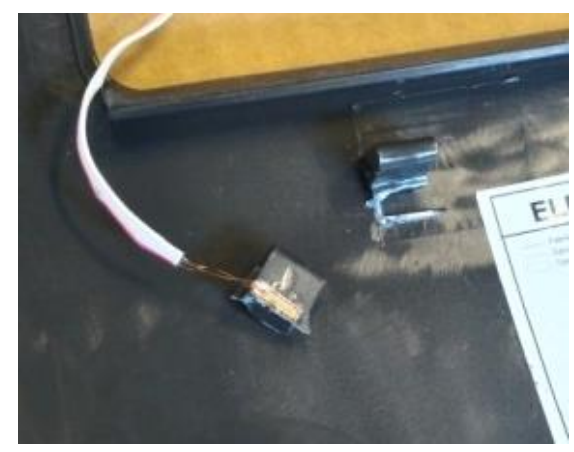

a) Drop test

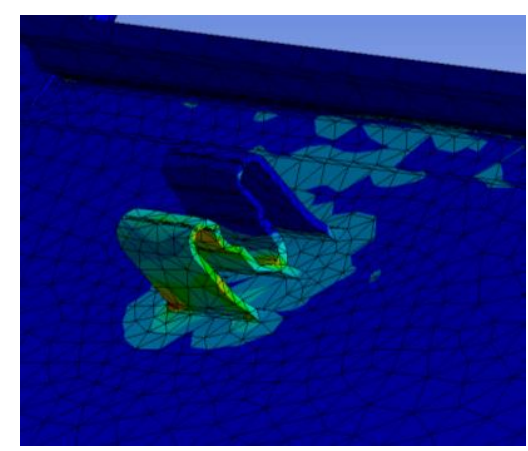

b) Finite Element Analysis

Figure 12. Deformation of décor hook

The measured parameters and their comparison for hooks of the decor and discharge grille are tabulated in Table 3.

The stress results of the strain gauge attached locations obtained from the physical drop test are compared with the FEM results to verify the reliability of these two methods. The difference of von Mises stress values obtained from drop test and analysis is negligible showing that the results are comparable and in agreement. Similar to previous studies for example washing machine [5] and refrigerator [8], the total average difference is less than $10 \%$. That small differences between von Mises stress values are thought to be mainly due to measurement accuracy of strain gauges and limited number of FEM noted considered analysis in order to reduce analysis time. 
Table 3. Comparison of measured and calculated von Mises stress values

\begin{tabular}{|c|c|c|c|c|c|c|c|}
\hline \multirow{2}{*}{$\begin{array}{l}\text { Ch } \\
\text { Name }\end{array}$} & \multirow{2}{*}{$\begin{array}{l}\text { Time } \\
\text { (msec.) }\end{array}$} & \multicolumn{3}{|c|}{ Decor } & \multicolumn{3}{|c|}{ Grille } \\
\hline & & $\begin{array}{l}\text { Strain } \\
\text { Gauge }\end{array}$ & ANSYS & \multirow{2}{*}{$\begin{array}{c}\text { Difference } \\
(\%)\end{array}$} & $\begin{array}{l}\text { Strain } \\
\text { Gauge }\end{array}$ & ANSYS & \multirow{2}{*}{$\begin{array}{c}\text { Difference } \\
(\%)\end{array}$} \\
\hline $\begin{array}{l}\text { Ch } \\
\text { No. }\end{array}$ & Ch1 & $\begin{array}{l}\text { Stress } \\
(\mathrm{MPa})\end{array}$ & $\begin{array}{l}\text { Stress } \\
(\mathrm{MPa})\end{array}$ & & $\begin{array}{l}\text { Stress } \\
(\mathrm{MPa})\end{array}$ & $\begin{array}{l}\text { Stress } \\
(\mathrm{MPa})\end{array}$ & \\
\hline 1 & 0 & 0,20 & 0,20 & 0 & 0,20 & 0,21 & -5 \\
\hline 2 & 4 & 0,30 & 0,29 & 3 & 0,30 & 0,32 & -7 \\
\hline 3 & 8 & 0,10 & 0,11 & -10 & 0,10 & 0,10 & 2 \\
\hline 4 & 12 & 0,40 & 0,41 & -2 & 0,40 & 0,39 & 3 \\
\hline 5 & 16 & 0,30 & 0,29 & 3 & 0,30 & 0,31 & -3 \\
\hline 6 & 20 & 255,20 & 245,00 & 4 & 97,10 & 92,00 & 5 \\
\hline 7 & 24 & 105,30 & 95,00 & 10 & 14,95 & 13,55 & 9 \\
\hline 8 & 28 & 0,22 & 0,24 & -9 & 0,23 & 0,25 & -9 \\
\hline 9 & 32 & 0,40 & 0,39 & 3 & 0,40 & 0,43 & -7 \\
\hline 10 & 36 & 0,11 & 0,12 & -9 & 0,16 & 0,17 & -6 \\
\hline 11 & 40 & 0,30 & 0,31 & -3 & 0,30 & 0,28 & 7 \\
\hline
\end{tabular}

After the validation of analysis, improvements are made in order to eliminate excessive deformations occurred in the drop test. A $1 \mathrm{~mm}$ round is added to bottom of decor hook rib as shown in Figure 13. Additionally, EPS is used in order to eliminate excessive deformation of discharge grille hook as shown in Figure 14.

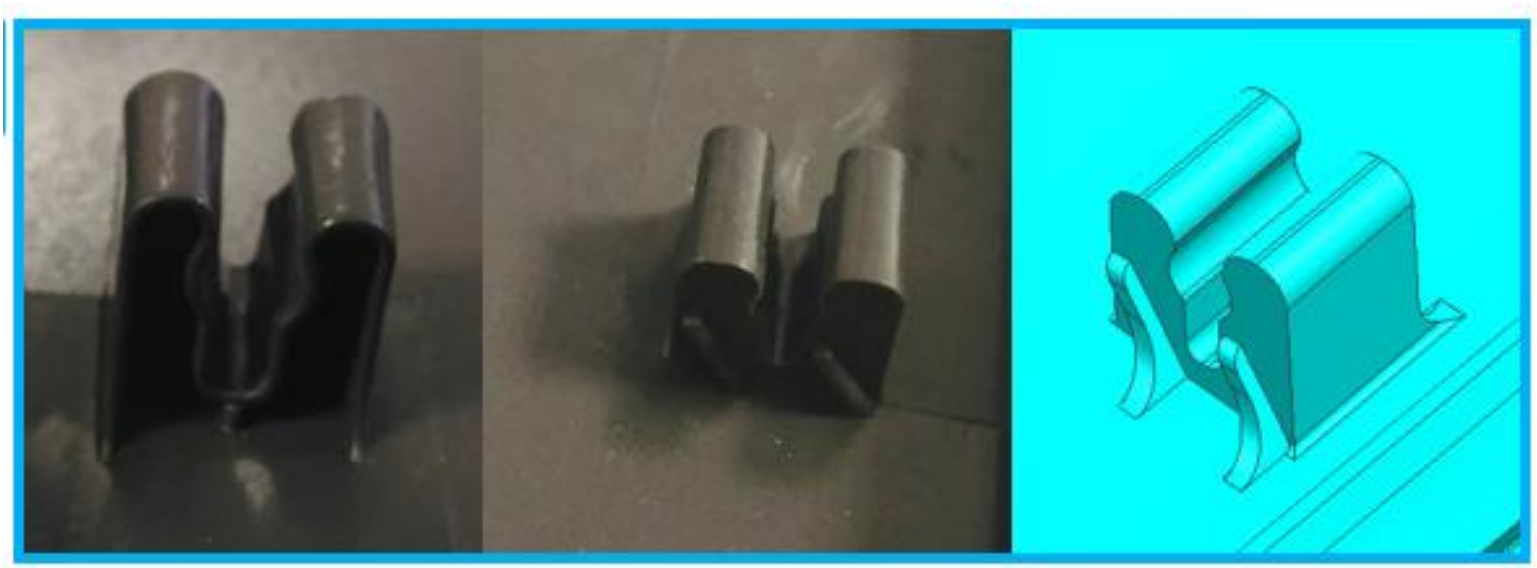

Figure 13. Round at the bottom of décor hook 


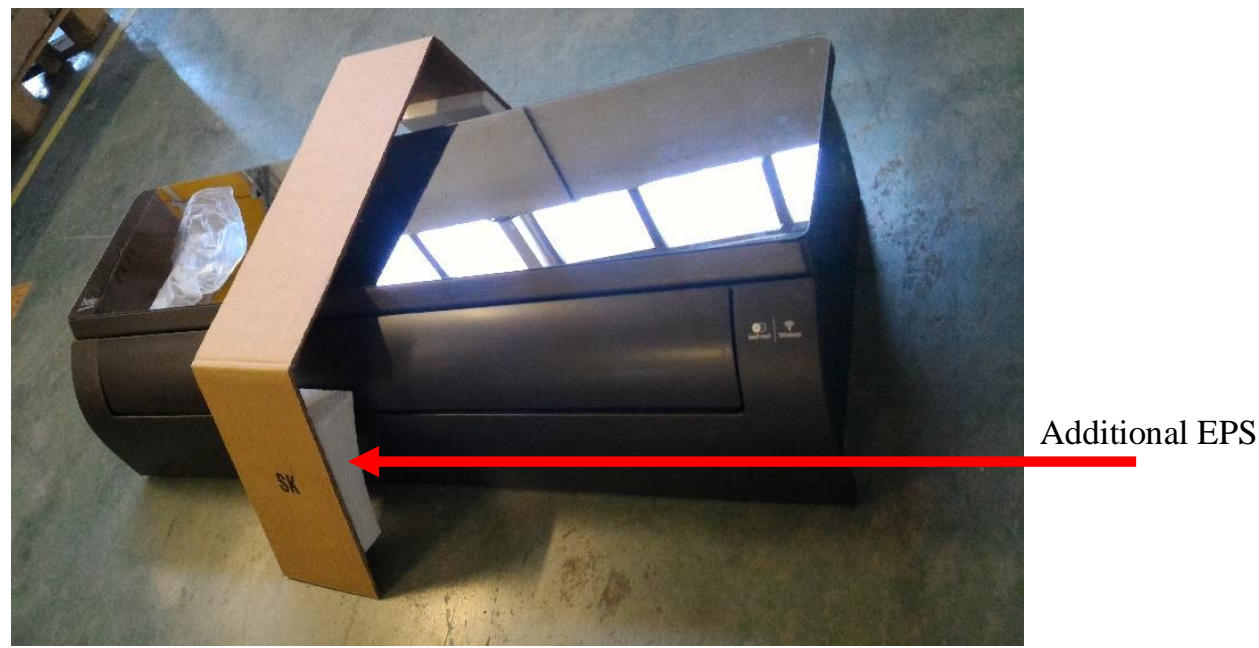

Figure 14. Additional EPS impeding deformation of discharge grille hook

After these improvements, the FEM analysis is repeated again. The von Mises stress results shown at the Table 4.

Table 4. Comparison of von Mises stress values between improved and unimproved hooks of décor and discharge grille parts

\begin{tabular}{|c|c|c|c|c|c|c|c|}
\hline \multirow[b]{2}{*}{$\begin{array}{l}\text { Ch } \\
\text { Name }\end{array}$} & \multirow[b]{2}{*}{$\begin{array}{l}\text { Time } \\
(\mathrm{msec} .)\end{array}$} & \multicolumn{3}{|c|}{ Decor } & \multicolumn{3}{|c|}{ Grille } \\
\hline & & $\begin{array}{l}\text { ANSYS } \\
\text { Stress for } \\
\text { (MPa) } \\
\text { Before Imp. }\end{array}$ & $\begin{array}{l}\text { ANSYS } \\
\text { Stress for } \\
\text { (MPa) After } \\
\text { Imp. }\end{array}$ & $\begin{array}{l}\text { Reduction } \\
(\%)\end{array}$ & $\begin{array}{c}\text { ANSYS } \\
\text { Stress for } \\
\text { Dis. (MPa) } \\
\text { Before } \\
\text { Imp. }\end{array}$ & $\begin{array}{l}\text { ANSYS } \\
\text { Stress for } \\
\text { Dis. (MPa) } \\
\text { After Imp. }\end{array}$ & $\begin{array}{l}\text { Reduction } \\
(\%)\end{array}$ \\
\hline 1 & 0 & 0,20 & 0,18 & 10,0 & 0,21 & 0,19 & 9,5 \\
\hline 2 & 4 & 0,29 & 0,31 & $-6,9$ & 0,32 & 0,27 & 15,6 \\
\hline 3 & 8 & 0,11 & 0,12 & $-9,1$ & 0,10 & 1,10 & $-1000,0$ \\
\hline 4 & 12 & 0,41 & 0,39 & 4,9 & 0,39 & 0,41 & $-5,1$ \\
\hline 5 & 16 & 0,29 & 0,32 & $-10,3$ & 0,31 & 0,28 & 9,7 \\
\hline 6 & 20 & 245,00 & 115,60 & 52,8 & 92,00 & 7,20 & 92,2 \\
\hline 7 & 24 & 95,00 & 48,90 & 48,5 & 13,55 & 1,30 & 90,4 \\
\hline 8 & 28 & 0,24 & 0,21 & 12,5 & 0,25 & 0,21 & 16,0 \\
\hline 9 & 32 & 0,39 & 0,41 & $-5,1$ & 0,43 & 0,39 & 9,3 \\
\hline 10 & 36 & 0,12 & 0,11 & 8,3 & 0,17 & 0,21 & $-23,5$ \\
\hline 11 & 40 & 0,31 & 0,27 & 12,9 & 0,28 & 0,25 & 10,7 \\
\hline
\end{tabular}

According to the analysis result, the maximum stress values decreased about 52,8\% for décor hook and $92,2 \%$ for discharge grille hook with respect to unimproved design data. New analysis results showed that the improvement is good enough. With these two modifications, the physical drop test is repeated and no excessive deformation and failure deformation is detected.

\section{CONCLUSIONS}

In this study, a wall-mounted air conditioner indoor unit is freely dropped into a rigid ground. The analysis results presented here are focused on stresses and deformations of the bottom critical parts, namely décor Additional EPS and grille; although similar analysis on other parts in the unit could also be conducted if 
required. Based on these analysis results, the design of these critical parts were improved. The experimental and numerical results on the improved parts are also in good agreement with each other.

It is found that the stresses and strains obtained using the Ansys Autodyn finite element code are compatible with the values obtained experimentally by using strain gauges, thus it can be concluded that the damages resulting from the impact can be accurately analysed by simulation.

Therefore drop tests can be performed in the early product design stages, eliminating the potential costs related with developing an inadequate product and last minute "band-aid" corrections to a poor design. Different test configurations and test parameters can be easily taken into account in the simulations.

After an initial design is simulated, the alternative design scenarios can be considered before finalizing the new design in cheap and fast way of simulations compared with experimental methods. Thus the virtual best design search can enable the development team to saves time and money, build less number of product prototypes that are destined for failure.

Simulating the drop test of air-conditioner indoor unit with FEM will have the following advantages;

- Lead time will decrease

- Time and money saving

- Identify critical areas for damage prevention

- Taking precautions in advance

This study can also be used as a guide for designing packaging materials and packaging geometries for impact sensitive products. Finally, this study also provides useful information for manufacturers to design better electric and electronic components as well as more robust products to withstand impacts and shocks under different loading conditions.

\section{CONFLICTS OF INTEREST}

No conflict of interest was declared by the authors.

\section{ACKNOWLEDGEMENT}

The authors would like to thank Marmara University BAPKO (Bilimsel Araştırma Projeleri Birimi) for their support through Project Number: BAPKO FEN-E-080415-0111.

Technical support provided by Arçelik-LG Klima Sanayi ve Tic. A.Ş (Turkey) is also well acknowledged.

\section{REFERENCES}

[1] ASTM D5276-98, Standard Test Method for Drop Test of Loaded Containers by Free Fall, (1998).

[2] ASTM D880-92, Standard Test Method for Impact Testing for Shipping Containers and Systems, (Reapproved 2015).

[3] Asa, T., "Modelling the drop test of household oven with finite element method", MSc Thesis, Istanbul Technical Univ., Istanbul, Turkey, (2015).

[4] Kim, W.J., Lee, B.Y., Son, B.S., "Drop-impact analysis and design of a package of a microwave oven", Trans. Korean Soc. Mech. Eng., 33: 536-543, (2009). 
[5] Kim, C.S., Bae, B.K., Sung, D.Y., "Drop analysis of a package and cushion performance of drum washing machine", Trans. Korean Soc. Mech. Eng., 34: 1733-1740, (2010).

[6] Mulkoglu, O., Guler, M.A., Demirbag, H., "Drop test simulation and verification of a dishwasher mechanical structure", Tenth European LS-DYNA Conference, Würzburg, Germany, (2015).

[7] Eraslan, S., "Modeling and drop test analysis of the built-in dish washer", MSc Thesis, Istanbul Technical Univ., Istanbul, Turkey, (2015).

[8] Hong, S., Choi, Y.C., Eom, S.U., Kim, H.L., Hyun, H.C., "Finite element analysis of dynamic deformation of refrigerator's lower hinge during drop test", Trans. Korean Soc. Mech. Eng., 3: 37-44, (2015).

[9] Oh, W., Lim, S., Park, K.S., Park, N.C., Park, Y.P., Lee, J.S., Lee, H.B., "Design of modified shock isolators for the optical pickup in an ADD by analytical and experimental Methods", Microsystem Technol., 19: 1615-1623, (2013).

[10] Lee, Y., Jung, U.J., Park, G.J., Han, I.S., Kim, T.K., "Optimization of the television packing system using equivalent static loads" Trans. Korean Soc. Mech. Eng., 39: 311-318, (2015).

[11] Low, K.H., Wang, Y., Hoon, K.H., Vahdati, N., "Initial global-local analysis for drop-impact effect study of TV products", Advances in Engineering Software, 35: 179-190, (2004).

[12] Yeh, M.K., Huang, T.H., "Drop test and finite element analysis of test board", Procedia Engineering, 79: 238-243, (2014).

[13] Zhou, C.Y., Yu, T.X., Lee, R.S.W., "Drop/impact tests and analysis of typical portable electronic devices", International Journal of Mechanical Sciences, 50: 905-917, (2008).

[14] Lacroix, C., Safran, G., "Modelisation of screen rupture during a mobile phone free fall", Sixth European LS-DYNA Conference, Gothenburg, Germany, (2007).

[15] Wu, I.C. , Wang, M. H., Jang, L.S., "Experimental location of damage in microelectronic solder joints after a board level reliability evaluation", Engineering Failure Analysis, 83: 131-140, (2018).

[16] Shah, Q.H., Topa, A., Modeling Large Deformation and Failure of Expanded Polystyrene Crushable Foam using LS-DYNA. Modelling and Simulation in Engineering, 1-7., 2014

[17] Yayla, P., Applied Theory of Elasticity (In Turkish), Nobel Academic Publisher, Ankara, Turkey, 2014

[18] BASF Inc., Packaging with Strafor, Access address: http://styropor.basf.us/files/pdf/Packaging_with_Styropor.pdf, Access date: 10.01.2020.

[19] ABS XG570, http://www.lgchem.com.tr/products/01122012-143947-astm-abs-xg570_eng.pdf, Access date: 10.01.2020. 